\title{
A amizade do sábio em Plotino
}

José Maria Zamora Calvo

(Universidad Autónoma de Madrid)*

The wise man does not look for anything else once he has reached the true Good, because he carries an autarchic and self-sufficient life and thereof distant from matter lives a happy life "alone with himself" (En. VI, 9[9] 11, 51). But, how is it that his selfsufficiency leads him towards an encounter with the other? The plotinian wise man does not stay isolated, rather, he is concerned about the state of other men and their ethical preoccupations. The spoudaîos/ $\sigma \pi 0 v \delta \alpha$ ĩos, lives with no fear, for he trusts himself fully, and tries to show the others the pre-eminence of life lived within intelligence. Having this as a purpose, he becomes the "best of all friends" (En. I, 4 [46] 15, 21-25). His friendship consists in valuing the superior part of man. This work reconstructs Plotinus notion of friendship throughout the Eneads. Friendship is compatible with wisdom, reason for which it becomes a central topic in his ethical theory. We, firstly, analyze the "other soul" of the wise man in contrast with the ordinary man, which lets him live independently from the sensible world and lets him positively value as pre-eminent what is inside of him. Then follows an analysis of the relations amongst magic, sympathy and the unity of soul. Thirdly, an analysis of the relations between happy life and intelligence, afterwards of the relations that autarchy and friendship have, and finally, as a conclusion, the study of pure Friendship of intelligible world.

A amizade ( $\varphi$ i ía) é um tema recorrente nas reflexões dos filósofos antigos. Desde o Lisis de Platão, passando pela Ética a Nicômaco (livros VIII e IX), a amizade figura como um tema central nas escolas helenísticas, especialmente em Epicuro e seus seguidores ${ }^{1}$. Entretanto, este tema, em Plotino, não foi ainda especificamente abordado. O homem sábio e de bem, pensado na ética do primeiro neoplatônico, se converte no melhor dos amigos.

\footnotetext{
* Este trabalho é parte integrante do Projeto co-financiado UAM-CM para criação ou consolidação de Grupos de Pesquisa da Universidade Autônoma de Madrid: "Influências das éticas gregas na filosofia contemporânea", Ref. CCG07-UAM/HUM-1499. A tradução para o português foi feita por Cícero Bezerra, a quem quero expressar minha gratidão.

${ }^{1}$ Cfr. Epicuro, Máximas capitales, 27, 28; Gnomologium Vaticanum Epicureum, 23, 28, 34, 39, 52, $56,61,66,78$.
} 
No tratado Sobre a felicidade I, 4 [46] Plotino diz que o sábio, pensado como aquele que encontrou o verdadeiro bem, não busca nada, pois leva uma "vida que bastase a si mesma", uma vida autárquica. Se o objetivo do filósofo é "fazer-se semelhante a deus" ${ }^{, 3}$ o resultado deste processo é a autarquia. A união do sábio com o Uno lhe propicia uma auto-suficiência, característica da unidade, frente ao múltiplo, dividido, que se mantém a margem pela falta e pela debilidade. Distanciando-se da matéria, o sábio vive uma vida feliz, "a sós com o Só", . Dito isto, como sua auto-suficiência lhe permite ir ao encontro do outro?

O objetivo deste artigo é estabelecer uma reconstrução do tema da amizade nos textos das Enéadas de Plotino. Trataremos de mostrar como a amizade se inscreve, de maneira primordial, na filosofia do alexandrino, resultando compatível com a sabedoria, o que faz dela um conceito fundamental da sua teoria ética. Começamos nossa análise com uma exposição da "outra alma" do sábio, que lhe permite "fugir" para mundo inteligível; seguiremos com um exame da magia, da simpatia e da unicidade da alma; da vida feliz e da inteligência; da relação entre a autarquia e a amizade; concluímos com o estudo da amizade pura, que caracteriza o mundo inteligível. Deste modo, trataremos de evidenciar o caráter específico da amizade em Plotino e a importância de sua doutrina para o debate filosófico.

\section{A “outra alma” do sábio}

2 En. I, 4 [46] 4, 23. O sábio "autárquico" foi tratado por Platão, Respublica, III, 387d-e; Aristóteles, Éthica Nicomachea, X, 7, 1177b; Epicuro, Epistula ad Menoeceum, 130; Sêneca, Epistulae

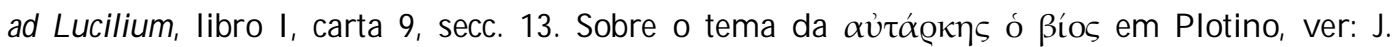
Laurent, "L'autarchie du sage selon Plotin", Études platoniciennes, III, 2006, pp. 131-139.

${ }^{3}$ Plotino segue o preceito platônico do Theaetetus, 176b2. Cfr. J.-F. Pradeau, "L'assimilation à dieu", en J. Laurent (ed.). Les dieux de Platon (Caen, Presses Universitaires, 2003), pp. 41-52.

4 En. VI, 9 [9] 11, 51: "Fugir só ao Só". Cfr. En. VI, 7 [38] 34, 7-8: "receber só ao Só" e En. I, 6 [24] 7, 9: "ver o uno por si só e a ele só". Sobre a origem e o significado desta expressão, pode-se

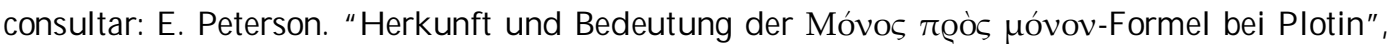
Philologus, 88, 1933, pp. 30-41, bem como, os comentários de M. J. Atkinson. Plotinus: Ennead V, 1. On the three principal hypostases. A commentary with translation (Oxford, Oxford University Press, 1983), pp. 131-132; P. A. Meijer. Plotinus on the Good or the One (Enneads VI 9). An analytical commentary (Amsterdam, J. C. Gieben, 1992), pp. 157-162; y P. Hadot, Traité 9, VI, 9, introduction, traduction et notes par P. H. (París, Cerf, 1994), pp. 51-53. 
No último capítulo do tratado Contra os gnósticos II, 9 [33], o final de uma grande tetralogia anti-gnóstica, Plotino afirma que imitando a alma do mundo, chegamos a uma outra contemplação: por nossos esforços podemos contemplar o objeto mesmo da alma do mundo, ou seja, o mundo inteligível ${ }^{5}$. O sábio plotiniano se diferencia do homem ordinário por sua capacidade de viver independentemente do mundo sensível, o que o leva a outorgar um estatuto preeminente àquele que se encontrar em si mesmo. O homem apresenta um estatuto de mediania entre $o$ mundo sensível e o inteligível e nisto reside sua capacidade de dirigir sua atenção para um ou para o outro. É importante ressaltar que ainda que se encontre no mundo sensível, o homem não está totalmente separado do inteligível, já que o nível superior de sua alma permanece unido a este último ${ }^{6}$.

Plotino ressalta a necessidade de que o homem fuja do mundo sensível e se separe dos elementos adicionais, isto é, do composto do corpo animado, no qual domina o corpo que possui um traço da alma. Nesta perspectiva, o homem é o que é graças a esta "outra alma" encarnada que lhe permite fugir para o mundo inteligível. É preciso que escute essa "outra alma", a alma encarnada, e não a alma vegetativa que lhe adere ao mundo sensível. Cumpre dizer que, embora busque harmonizar sua alma com o mundo inteligível, entre o mundo inteligível e o sensível não há uma ruptura, mas uma continuidade, dito de outro modo, o mundo sensível é uma imagem, a mais bela imagem possível do mundo inteligível e, neste sentido, o homem deve buscar a concordância com o mundo sensível não implicando, com isso, distanciar-se do mundo inteligível.

$\mathrm{Na}$ crítica dirigida aos gnósticos, Plotino rechaça a incoerência daquele que não reconhece no mundo sensível uma imagem do inteligível ${ }^{7}$. Plotino recorre ao Banquete ${ }^{8}$ de Platão para afirmar que as belezas no mundo sensível permitem, ao homem, elevarse gradualmente em direção à beleza inteligível. Insiste na necessidade do homem elevar-se, não somente das belezas situadas no mundo sensível em direção ao verdadeiramente belo, mas também de distanciar-se das coisas sensíveis, alcançando,

\footnotetext{
${ }^{5}$ Cfr. En. II, 9 [33] 18, 30-35.

${ }^{6}$ Cfr. En. VI, 4 [22] 14, 21-23.

${ }^{7}$ Cfr. En. II, 9 [33] 8, 15-16.

${ }^{8}$ Cfr. Platão, Symposium, 211c.
} 
deste modo, a contemplação do mundo inteligível. Portanto, é preciso que se aparte do que não é propriamente si mesmo e siga o preceito platônico de "fugir daqui para lá" 9 . Para ascender à contemplação do inteligível, o homem deve distanciar-se do mundo sensível, ou bem recorrendo as etapas sucessivas, ou bem por uma fuga. É importante dizer que, para Plotino, esta fuga não deve ser interpretada como um movimento de um lugar a outro, que teria como ponto de partida um lugar situado fora de nós mesmos e como ponto de chegada outro lugar também exterior ${ }^{10}$. Diferentemente de uma viagem espacial, fugir consiste em despertar para uma visão interior e, baseando-se na leitura do Teeteto $^{11}$, chegar a ser virtuoso. Deste modo, fugir permite separar-se de tudo o que é exterior, escapar tanto dos desejos como dos temores que provêm da alma irracional, para voltar-se a si mesmo e ver, assim, no interior o mundo inteligível. Assim, por meio desta purificação, a fuga se identifica com uma visão interior das formas inteligíveis, o que permite, ao homem, identificar-se com o próprio mundo inteligível ${ }^{12}$. Diferentemente da ação, orientada ao exterior, a purificação, que possibilita a contemplação, põe o homem de frente consigo mesmo. A visão interior das formas inteligíveis conduz o homem, ao separar-lhe da multiplicidade, à sua unidade verdadeira.

Deste modo, o homem bom e virtuoso fica protegido do encantamento, produzido pela atração do sensível, já que sabe que este é somente uma imagem do inteligível, sem, no entanto, desprezá-lo, porque é uma bela imagem do inteligível. A contemplação do inteligível é, ao mesmo tempo, a condição da liberdade do homem com relação à atração que exerce o sensível e o fim da evasão.

\section{Magia, simpatia e unicidade da alma}

\footnotetext{
${ }^{9}$ Platão, Theaetetus, 176a8-b1 e a referência de Plotino em En. II, 3 [52] 9, 19-20. Cfr. En. I, 1 [6] 8, 8 y 16; V, 9 [5] 2, 5-9; VI, 9 [9] 11, 51; III, 4 [15] 2, 12; I, 2 [19] 1, 3; II, 9 [33] 6, 39-41; I, 8 [51] 6, 9-13 y $7,12-14$.

${ }^{10}$ Cfr. En. I, 6 [1] 8, 22-27; I, 8 [51] 6, 9-13 y 7, 12-14. Sobre este ponto, ver T. Vidart. "'Il faut s'enfuir d'ici': la relation de l'homme au monde", Études platoniciennes, III, 2006, pp. 141-152.

${ }^{11}$ Cfr. Platão, Theaetetus, 176a-b.

${ }^{12}$ Cfr. En. IV, 7 [2] 10, 30-40.
} 
Para Plotino, a magia não se manifesta somente no contexto dos artifícios preparados pelos indivíduos aos que outorga uma série de poderes particulares, mas também, no marco da própria natureza, pela simpatia que relaciona todas as coisas em uma unidade orgânica ${ }^{13}$.

Ainda que professando admiração e afeto por estas coisas, por que as

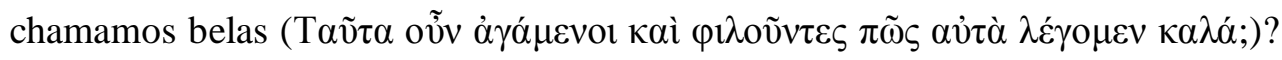
É verdade que estas são, e isto é visível, e não há necessidade de que quem as veja as chamem de outro modo, mas como realmente são. No entanto, o que realmente são? Belas. Com tudo, a razão carece de uma explicação. O que é que as fazem ser desejáveis pela alma? O que é essa espécie de luz que brilha em

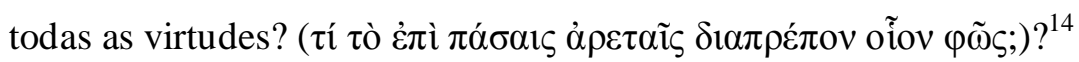

Esta "espécie de luz que brilha em todas as virtudes", isto é, nas perfeitas, é o resplendor da inteligência ${ }^{15}$. As coisas derivadas da inteligência são os logoi que embelezam a alma: são seus ornamentos ${ }^{16}$. A alma constitui a "matéria psíquica" com relação à inteligência e ao $\log o s^{17}$. Disto resulta que a inteligência e o logos sejam a forma própria da alma, o que faz que esta seja plenamente alma. O resplendor da inteligência, que caracteriza as virtudes superiores ou perfeitas, pode refletir-se no semblante do virtuoso ${ }^{18}$. O homem de bem, se realmente é um homem de bem, sempre se mantém jovial, conservando um estado constante de serenidade e um talante que não sofre nenhum tipo de perturbação derivada de supostos males ${ }^{19}$.

\footnotetext{
${ }^{13}$ Sobre a definição plotiniana da magia, ver: En. IV , 4 [28] 40, 1-6; 43, 21-24 y 44, 29-33.

${ }^{14}$ En. I, 6 [1] 5, 17-22.

${ }^{15}$ Cfr. En. I, 2 [19] 4, 19-20; 6, 12-27.

${ }^{16}$ Cfr. En. III, 5 [50] 9.

${ }^{17}$ Cfr. En. II, 4 [12] 3, 4-5; V, 8 [31] 3, 3-9.

18 Porfirio, Vita Plotini, 13, 5-10: “Ao falar, a inteligência transparecia até em seu rosto, iluminando-o com sua luz; ele já possuía um encanto que embelezava a vista, no entanto, mais que nunca se tornava visível; banhando-lhe um suor tênue, irradiava tranqüilidade e, às perguntas, respondia com mostras tanto de bondade como de energia". Na atividade, essência de sua vida, o ensino, Plotino mostrava sua autêntica natureza: seu voṽ s aparecia refletido em seu rosto.

${ }^{19}$ Cfr. En. I, 4 [46]12, 7-11.
} 
O tratado Sobre se os astros influem II, 3 [52], anti-penúltimo na ordem cronológica $^{20}$, que aborda o tema da astrologia, Plotino aceita, embora com reservas, a simpatia cósmica da Stoa e se opõe claramente à fabulação mitológica dos astrólogos como incompatível com a divindade, imutabilidade dos astros e contrária à universal subordinação do mundo sensível a único princípio. Em sua refutação das teorias astrológicas, considera absurdo pensar que os planetas variam de humor em função de sua passagem pelo zodíaco, de suas fases e de seus aspectos.

Plotino aponta para a possibilidade dos planetas fazerem o que fazem não porque desejam, mas impelidos por suas relações com cada um de nós. A crítica à astrologia é feita aceitando, portanto, a doutrina da simpatia cósmica. Não nega que haja influências que emanam das estrelas, como de outras partes do universo e, também, não rejeita a possibilidade de que as estrelas possam, por esta mesma razão, servir como signos do que está sucedendo, ou do que sucederá no mundo sublunar, mas rechaça drasticamente que as estrelas sejam causas do que acontece na terra, ou de que elas estejam associadas, de algum modo, com os seres que ocupam uma posição inferior na hierarquia. Em sua crítica à astrologia, Plotino permanece fiel à tradição platônica ${ }^{21}$.

E dizer que tal planeta se alegra quando se encontra na casa de um outro, mas que a este lhe sucede o contrário quando se encontra na casa daquele, não é verdade que é como se um, depois de supor que dois homens são amigos um do outro, dissesse logo em seguida que um ama o outro, mas que este o odeia?

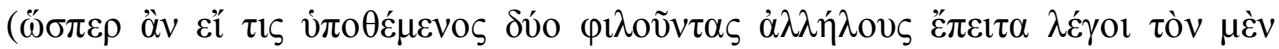

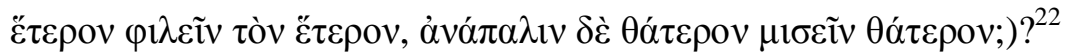

Cada planeta tem sua própria "casa" em um dos signos do zodíaco, naquele onde se encontra mais a gosto e mais ativo.

É que a honra mesma que eles atribuem aos deuses inteligíveis carecerá de simpatia já que quem professa carinho a um ser qualquer, sente afeto também

\footnotetext{
${ }^{20}$ Cfr. Porfirio, Vita Plotini, 6, 20.

${ }^{21}$ Cfr. J. Dillon. "Plotino y su tratado, Sobre si los astros influyen [Enn. II 3]", MHNH. Revista Internacional de Investigación sobre Magia y Astrología Antiguas, 3, 2003, pp. 149-158.

${ }^{22}$ En. II, 3 [48] 4, 13-16.
} 
enquanto está irmanado com o ser querido; assim, se afeta com os filhos o pai

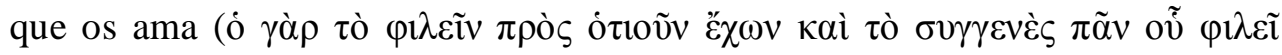

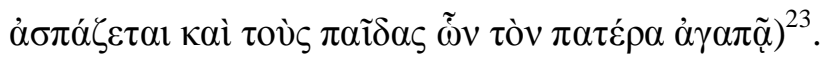

O logos que reside em cada um de nós, que serve para diferenciar nossas almas inclusive da alma do Mundo (da que seríamos somente partes) assegura que somos, cada um, membros individuais do mundo das formas inteligíveis ${ }^{24}$. Plotino se separa da Stoa e regressa à posição platônica sobre a autonomia da alma racional, para defender a autonomia da razão frente às influências do cosmos, astrais ou de outro tipo. No entanto, nos tratados mais tardios, como no Sobre a providência III 2-3 [47-48], matiza sua tese precedente, afirmando que o curso do Logos universal também está fixado, mas que nós, enquanto partes dele, somos, no entanto, autônomos, porque sua decisão original é nossa decisão. Deste modo, Plotino desconsidera a submissão estóica à necessidade universal ${ }^{25}$. Os estóicos concebem a alma individual como uma parte da alma universal e, portanto, não autônoma. Para Plotino, cada um de nós constitui um logos distinto e, por isso, uma forma distinta, coextensiva com a própria Inteligência, produtora da ordem no mundo, pela mediação da Alma.

Em um dos primeiros tratados redigidos por Plotino, intitulado Sobre se todas as almas são uma só IV 9 [8], em que aborda o tema da "unimultiplicidade" da Alma, defende a tese de que todas as almas encarnadas, tanto a do cosmos como as almas humanas, são almas particulares que provem de uma só anterior a todas: a Alma superior. Assim, todas as almas são uma só, conformam uma única hipóstase, una e múltipla, henologicamente anfíbia: una e indivisa em seu nível superior, intelectivoracional, ao mesmo tempo em que é múltipla e indivisamente dividida em seu nível inferior, físico ou sensitivo-vegetativo ${ }^{26}$. A afecção do conjunto repercute na parte mais facilmente que a afecção da parte no conjunto ${ }^{27}$. Os fenômenos da simpatia e magia confirmam a unicidade da alma:

\footnotetext{
${ }^{23}$ En. II, 9 [33] 16, 7-9.

${ }^{24}$ Cfr. En. V, 7 [18]; III, 1 [3] 9, 10-17.

${ }^{25}$ Cfr. A. Graeser. Plotinus and the Stoics (Leiden, Brill, 1972), pp. 112-25.

${ }^{26}$ Cfr. En. IV , 3-5 [27-29]. Ainda que a alma seja una e indivisa, ao mesmo tempo, é múltipla e divisível.

${ }^{27}$ Cfr. En. IV, 9 [8] 2, 24-33.
} 
De modo que, baseando-se nos fatos provenientes de signos contrários, a

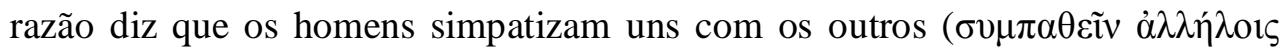
$\dot{\eta} \mu \tilde{\alpha} \varsigma)$ quando, ao nos vermos, nos compadecemos e nos sentimos relaxados e

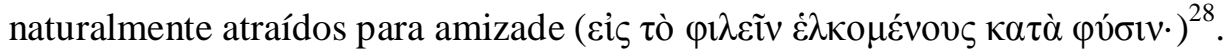

A amizade se deve à unicidade da alma.

E se os encantamentos e as artes mágicas, em geral, logram que nos juntemos e simpatizemos desde longe, isso é possível sem dúvida pela unidade da alma $(\delta i \grave{\alpha} \psi v \chi \tilde{\eta} \varsigma \mu 1 \tilde{\alpha} \varsigma)^{29}$.

A magia se explica por "simpatia" e por "conexão", ou seja, porque para Plotino é inerente à natureza que haja sintonia entre semelhantes e oposição entre dessemelhantes. Esta magia "natural", que se baseia na simpatia ou antipatia naturais entre semelhantes ou dessemelhantes respectivamente, se diferencia da magia "artificial", uma arte auxiliar da natureza que se baseia no conhecimento ${ }^{30}$. Para explicar isto, Plotino faz alusão às duas forças que alternam seu domínio na cosmologia de Empédocles ${ }^{31}$, ao mesmo tempo em que aplica ao universo o que Platão diz do Amor no Banquete $e^{32}$ : "A verdadeira magia consiste na "Amizade" e "Discórdia" que alternam no universo, e o primeiro mago e feiticeiro é o universo; e como há homens que o

\footnotetext{
${ }^{28}$ En. IV, 9 [8] 3, 1-3. Sobre o problema da "unimultiplicidade" da alma, ver H.-J. Blumenthal. "Soul, World-Soul and Individual Soul in Plotinus", en Le Néoplatonisme (París, C.N.R.S., 1971), pp. 55-63.

${ }^{29} \mathrm{En}$. IV, 9 [8] 3, 3-6.

${ }^{30} \mathrm{Cfr}$. En. IV, 4 [28] 40.

${ }^{31}$ Cfr. Empédocles, Frs. 17, 7-8 y 26, 5-6. Cfr. En. V, 1 [10] 9, 6-8: “Para Empédocles a ‘Discórdia' dissocia e a 'Amizade' é o Uno; a este o concebe, também, como incorpóreo e os elementos são a modo de matéria". Sobre a concepção do Uno como incorpóreo, ver: Aristóteles, Metafísica, 985a7, 28; 1001a12-15. Sobre os elementos concebidos a modo de matéria, ver: II 4, 7, 1-2: "Empédocles, ao colocar os elementos em qualidade de matéria, tem em conta o testemunho da corrupção daqueles". Cfr. Aristóteles, Acerca de la generación y corrupción, II, 6. Por sua parte, Empédocles não fala dos quatro elementos como "matéria", mas como "raízes" (cfr. Fr. 6).

${ }^{32}$ Cfr. Platão, Symposium, $203 \mathrm{~d} 8$.
} 
conhecem a fundo, se valem de suas drogas e de seus feitiços para atuar uns sobre outros",33.

Plotino se enfrenta, em primeiro lugar, com Empédocles: a matéria não se identifica com os elementos, pois estes se corrompem. É necessário que haja um substrato permanente da geração e da corrupção ${ }^{34}$. "Empédocles, ao pôr os elementos

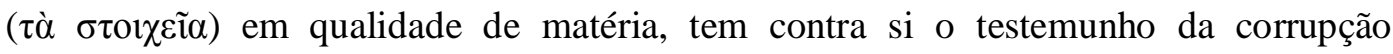

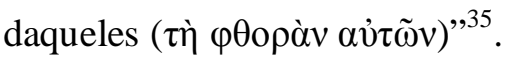

No entanto, Empédocles não faz alusão aos quatro elementos como matéria, mas como "raízes" 36 . Empédocles nos fala de um processo dual constituído pela gênese do uno a partir do múltiplo e, por sua vez, do múltiplo a partir do uno ${ }^{37}$. O universo se produz por um processo de mistura e separação de quatro elementos ou raízes (terra, água, ar e fogo), dominados pela atividade alternante do Amor (

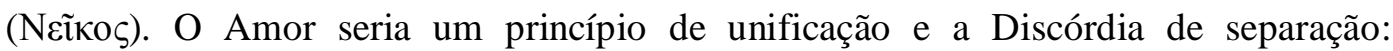
enquanto a Discórdia está no conflito com as quatro raízes, o Amor está em harmonia com elas.

O cosmos sensível, que é múltiplo e está fracionado em uma multiplicidade, vem à existência graças ao cosmos inteligível, que é verdadeiro e uno. No mundo sensível "uma parte está distanciada de outra e convertida em sua estranha; e, a causa deste distanciamento, já não reina só a Amizade ( $\varphi$ i ía), mas também, a Inimizade

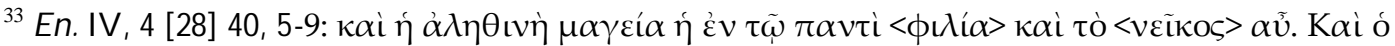

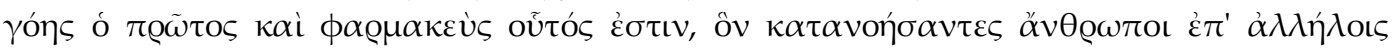

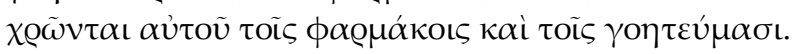

${ }^{34}$ Cfr. Aristóteles, De generatione et corruptione, B 2, 330 a 30 y ss.; 325 b; y Metaphysica, B 4, 1000 b 17-20.

${ }^{35}$ Cfr. En. II, 4 [12] 7, 1-2.

${ }^{36}$ Cfr. Empédocles, Fr. 6 (Aecio, I, 3, 20): “Escuta primeiro as quatro raízes (@̊ı $\zeta \omega \mu \alpha \tau \alpha$ ) de todas as coisas: Zeus resplandecente, Hera doadora de vida, Edoneo e Nestis, que com suas lágrimas enchem as fontes dos mortais"; e Aristóteles: Metaphysica, A 4, 985 a 31-33 (DK 31 A 37): “(...) foi

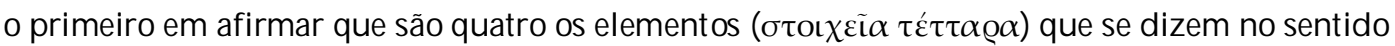
de 'matéria'".

${ }^{37}$ Cfr. Empédocles, Fr. 17, 1-13 (Simplicio, In Aristotelis Physica commentaria, 158, 1). Sobre a noção de matéria em Empédocles, ver: Th. G. Sinnige. Matter and infinity in the Presocratic Schools and Plato (Assen, Var Gorcum, 19712), pp. 11-117 y pp. 198-201; assim como C. Baeumker. Das Problem der Materie in der griechischen Philosophie. Eine historisch-kritische Untersuchung (Münster, 1890), pp. 67-72, y A. Rivaud, Le problème du devenir et la notion de la matière dans la philosophie grecque depuis les origines jusqu'à Théophraste (París, Félix Alcan, 1905), pp. 121-125.
} 


\section{Journal of Ancient Philosophy Vol. II 2008 Issue 1}

$(\varepsilon ้ \chi \theta \rho \alpha)^{, 38}$. Como a parte não é autárquica, mas se conserva graças a uma outra, é hostil a aquela pela qual se conserva. O cosmos sensível se originou não em virtude de um cálculo, como o artesão, mas pela necessidade da existência de uma segunda natureza ${ }^{39}$.

Em cada nível da realidade Plotino distingue duas classes de atividades: 1) a própria atividade da essência de cada coisa, que a define, e 2) a que resulta da essência de cada coisa, que deriva da primeira, mas se diferencia dela ${ }^{40}$. Plotino compara esta dupla atividade com o fogo, que possui um calor imanente e outro transmitido por ele ${ }^{41}$. Trata-se, segundo Rutten, de um princípio de validez universal, mas com uma aplicação analógica $^{42}$. Este princípio da dupla atividade, por ser de validez universal, serve para explicar o mecanismo da processão como transmissão em cadeia de um fluxo vital. Assim, cada termo, ao mesmo tempo em que está constituído essencialmente por uma atividade, é também transmissor de uma nova atividade. No entanto, como sua aplicação é analógica, Plotino a utiliza inclusive para o primeiro princípio. Ainda que o Uno-Bem esteja situado mais além da vida, do pensar e do ser, não se pode falar de uma atividade constitutiva de sua essência, mas somente de uma pré-vida, pré-pensamento, pré-atividade, que em realidade são supra-vida, supra-pensamento, supra-atividade, que seria o mesmo que vida, pensar e atividade por analogia.

No tratado Problemas acerca da alma (II) [28], Plotino nos apresenta uma análise mais sistemática da unidade do universo e da função da simpatia ${ }^{43}$. A referência

${ }^{38}$ En. III, 2 [47] 2, 3-5.

${ }^{39}$ Cfr. En. II, 9 [33] 8, 20-29.

${ }^{40}$ Cfr. En. V, 4 [7] 2, 27-30. Sobre a dupla atividade, ver: Ch. Rutten. "La doctrine des deux actes dans la philosophie de Plotin", Revue philosophique de la France et de léétranger, 81, 1956, pp. 100106.

${ }^{41}$ Cfr. En. V, 1 [10] 3, 10 y En. V, 4 [7] 2, 30-33.

${ }^{42}$ Cfr. Ch. Rutten, art. cit., 101.

${ }^{43}$ Cfr. En. IV, 4 [28] 8, 52-61; 23, 9-29; 26, 1-15; 32, 13-22; 34, 9-13; 34, 26-33; 35, 8-16; 40, 1-4; y 41,

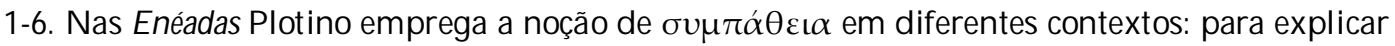
a eficácia da magia e das preces, a influência dos corpos celestes, assim como a transmissão visual e acústica (cfr. En. IV , 4 [28] 26, 1-20; IV, 5 [29] 2, 15-23; IV, 9 [8] 3, 1-21). O cosmos é um animal uno e múltiplo, em simpatia consigo mesmo, e as partes semelhantes, ainda que não sejam contíguas, "sintonizam" entre elas como as cordas de uma lira, de tal modo que o que afeta uma parte repercute em outra por simpatia (cfr. IV, 4 [28] 8, 56-57; 41, 1-6). Embora a noção plotiniana de $\sigma v \mu \pi \alpha \dot{\theta} \theta \varepsilon \iota \alpha$ difere da estóica. Para Plotino a $\sigma v \mu \pi \alpha ́ \alpha \varepsilon \varepsilon\llcorner\alpha$ só pode dar-se na estrutura de um organismo, mas, à diferença dos estóicos, a alma é incorpórea e pertence ao mundo transcendente. Sobre este tema, ver: J. Mª Zamora. "Entre la Academia y el Pórtico. La sympátheia en Plotino", Revista Latinoamericana de Filosofía, 29, 2003, pp. 97-122. 


\section{Journal of Ancient Philosophy Vol. II 2008 Issue 1}

à $\sigma 0 \mu \pi \alpha ́ \theta \varepsilon 1 \alpha$ é feita em conexão com o conhecimento das preces e a magia, explicada pela harmonia dos astros ${ }^{44}$. As artes divinatórias, a magia e as preces são fenômenos que Plotino não nega, mas que situa em relação com elementos transcendentes. Trata-se de aspectos derivados da inter-relação material das diversas partes deste universo.

A magia se explica por "simpatia" e por "conexão" de umas partes com outras.

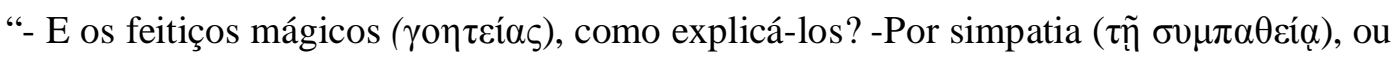
seja, porque é inerente a natureza que haja sintonia entre semelhantes ( $\sigma 0 \mu \varphi \omega v i ́ \alpha v$ cĩval

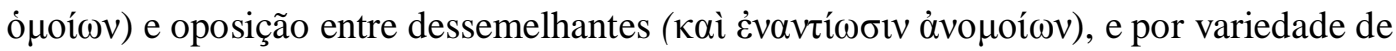
potências das muitas coisas que confluem em um animal unitário ( $\tilde{\varepsilon} v \zeta \tilde{\omega} \mathrm{o} o v)$ " ${ }^{45}$. Plotino utiliza a explicação da simpatia sem cair no determinismo materialista de seus predecessores, a fim de preservar a integridade individual sem perder a unidade fundamental destes indivíduos como membros de um todo unitário.

A origem da simpatia na alma não se reduz à manifestação da simpatia no nível do universo físico. Este nível materialista não faz efeito em termos de uma parte que está em sintonia com outra, usando a imagem musical, que aparece com freqüência nas Enéadas $^{46}$. A simpatia é descrita como uma influência mútua das partes com respeito a outras e ao todo, preservando no nível material o que concerne ao individual, além da totalidade.

Plotino descreve a simpatia como a relação de uma parte do universo com outra em temos de similaridade ou sintonia. Trata-se de um aspecto importante da simpatia em relação à estrutura do universo. Mas também a percepção sensível do mundo nasce do caráter simpático do universo como um todo e ele mesmo expressa a auto-implicação interna do ser vivo e a capacidade desse ser vivo de ser afetado e relacionado com outro. Da problemática da unidade material do universo como um todo Plotino passa para a unidade individual de cada um.

\footnotetext{
${ }^{44}$ En. IV, 4 [28] 41, 1-6: “Mas o sol ou outro astro não se dá conta; de modo que o influxo correspondente a oração se deve a que uma parte entrou em simpatia com outra, como ocorre em uma mesma corda quando está estendida: ao vibrar pela parte de abaixo, vibra também acima, e quase sempre a vibração de uma corda como se sente em uma outra por sintonia e

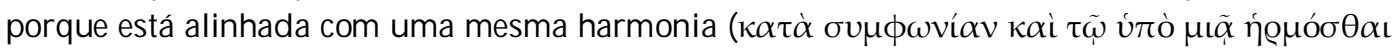

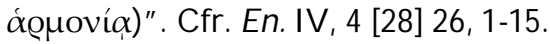

${ }^{45} \mathrm{En}$. IV, 4 [28] 40, 1-4.

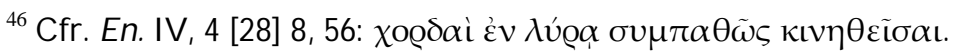


O universo sensível plotiniano se compõe de uma multidão de seres, não o obstante, se mantém como "uno", pois os seres que o integram estão em harmonia com o Todo e com eles mesmos. O Todo é um organismo e forma "um mundo ordenado"

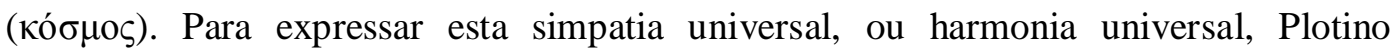
emprega a imagem da dança, em que cada movimento contribui para a beleza do conjunto $^{47}$. A imagem do bailarino se adapta a vida do universo, ao ponto de Plotino designar esta vida como "a dança do universo" 48.

\section{A vida feliz e a inteligência}

No primeiro tratado que compôs depois da ida de Porfírio à Sicília, fruto de uma depressão que quase o levou ao suicídio $^{49}$, Plotino analisa o tema da verdadeira felicidade à luz da distinção fundamental de sua antropologia entre o "eu superior" e o "eu inferior" do homem ${ }^{50}$. A verdadeira felicidade consiste na vida do "eu superior", que não tem porque ver-se afetada (nem diminuída nem aumentada) pela do "eu inferior". Assim, a felicidade consiste na vida da inteligência, ou seja, nem na "vida" em geral, entendida no sentido unívoco, nem na "vida racional", entendida como soma de gênero e diferença específica ${ }^{51}$, mas na vida de primeiro grau e perfeito, que é a própria da inteligência e consubstancial a ela ${ }^{52}$.

Todo homem, pelo fato de ser, está dotado de inteligência e é, por isso mesmo, feliz em potência; não o obstante, só o sábio é feliz em ato, porque só ele possui inteligência perfeita ou sábia ${ }^{53}$. O homem sábio, que possui esta vida de primeiro grau e

\footnotetext{
${ }^{47} \mathrm{Cfr}$. En. IV , 4 [28] 34, 26-33: “Em conclusão, esta doutrina atribui virtualidades às figuras, mas também atribuem virtualidades aos astros configurados. Pois é um fato que as duas mãos e os outros membros dos dançantes possuem certa virtualidade; mas também a possuem, e grande, as figuras coreográficas; vem em terceiro lugar os elementos concomitantes; as partes dos membros empregados para a dança e as partes de que constam essas partes, por exemplo as partes contraídas das mãos e os tendões e veias co-afetadas".

${ }^{48}$ Cfr. En. IV, 4 [28] 35, 8-16.

${ }^{49}$ Cfr. Porfirio, Vita Plotini, 6, 1-5; 11, 11-15.

${ }^{50}$ En. I, 4 [46]: Sobre la felicidad.

${ }^{51}$ Cfr. En. I, 4 [46] 3, 1-16.

${ }^{52}$ Cfr. En. I, 4 [46] 3, 16-40.

${ }^{53}$ Cfr. I, [20] 3, 28; I, 4 [46] 4, 1-20.
} 
perfeita, não necessita de nenhum outro bem e é impassível a todo mal. O mesmo é para si mesmo o bem mesmo que possui. O Bem transcendente é causa de seu bem imanente, e está presente nele de outro modo. Como se encontra neste estado de perfeição, pela identificação de seu eu com o nível intelectivo, não busca outra coisa distinta de si mesmo. A vida que leva basta-se a si mesma, e as outras coisas, desejadas pelos níveis sub-intelectivos passam a ser acessórias. Portanto, se alguém é virtuoso, basta-se a si mesmo para a felicidade e para a consecução do bem.

De modo que nem em meio das adversidades sofrerá diminuição da sua felicidade, já que, assim e todo, tal vida é permanente. E caso morram seus

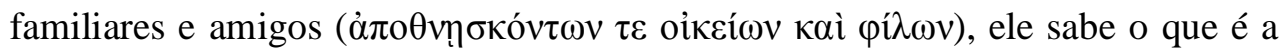
morte. Sabem também os que padecem, se são virtuosos (oi $\pi \alpha ́ \sigma \chi 0 v \tau \varepsilon \varsigma$ $\sigma \pi 0 v \delta \alpha i ̃ o t ~ o ̋ v \varepsilon \varsigma)$. Mas a morte padecida por familiares e próximos, ainda que

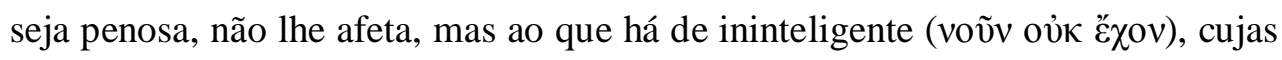

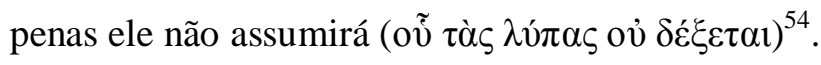

A vida feliz não se vê afetada por calamidades, desastres, enfermidades ou dores, nem pela perda ou falta de consciência, nem por nenhuma coisa externa ${ }^{55}$. Na vida de seu "eu superior", vive conforme o Bem, sem deixar, por isso, de ser amável com o "eu inferior" 56 . Como o músico com sua lira, manterá com ela, enquanto possa servir-se dela. Mas, do contrário, mudará por outra, prescindirá dela ou se absterá de ter-la, deixando como Bécquer a harpa esquecida, ocupando-se de outras coisas, "sem a lira, que permanecerá esquecida próxima dele, enquanto ele canta sem instrumentos" ${ }^{\text {}}$.

\section{Autarquia e amizade}

A união do sábio com o Uno-Bem conduz a autarquia, ao ponto da existência mesma do mundo passar a ser indiferente para ele. A alma do sábio, quando vê as

\footnotetext{
${ }^{54}$ En. I, 4 [46] 4, 32-36.

${ }^{55}$ Cfr. En. I, 4 [46] 5-11.

${ }^{56}$ Cfr. En. I, 4 [46] 16.

${ }^{57} \mathrm{En}$. I, 4 [46]16, 26-27.
} 
formas, quando está identificada com o Noûs ainda é ela mesma, mas, quando alcança o Uno, tem um tipo de vida diferente, que não se pode expressar, mas que se experimenta. Mais além do sensível e do inteligível, a alma do sábio se une ao primeiro princípio, que é não-ser $\mu$ ஸ̀ ǒv, pelo que esta assimilação consiste em uma "nadificação".

E todas as demais coisas nas que antes se deleitava -mandos, poderes, riquezas, belezas, ciências- de todas estas coisas fala com desdém. Não falaria assim se não houvesse encontrado outras melhores. E não tem medo de que lhe ocorra algo, estando como está com aquele, e não meramente olhando-o. E se

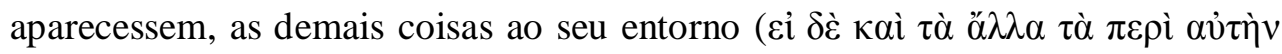
$\varphi \theta$ cípoıนo), com boa vontade acederia a ele ou para estar a sós junto àquele. Tal é o grau de bem estar a que há chegado (

O sábio que experimenta a união com o Uno sabe que não necessita nada, nem beleza, nem ser, se encontra em um estado de pura autarquia, de tal modo que o eu abandona tudo exceto o "bem estar" ( $\varepsilon \dot{\pi} \pi \alpha \dot{\theta} \varepsilon 1 \alpha)$.

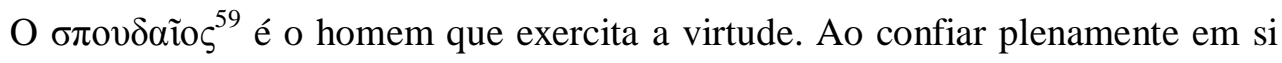
mesmo, vive sem temor. Caso assemelhasse a algo, não seria perfeito em virtude. $\mathrm{O}$ homem sábio e de bem trata de mostrar ao outro a preeminência da vida na inteligência, e com este propósito se converte no melhor dos amigos:

\footnotetext{
${ }^{58} \mathrm{En}$. VI, 7 [38] 34, 31-38.

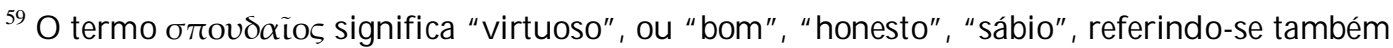

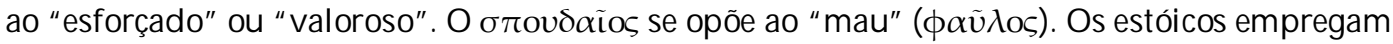

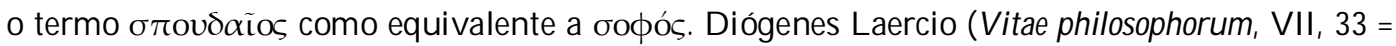

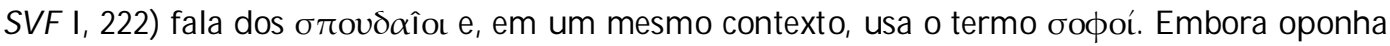

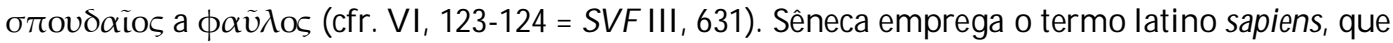
corresponde ao grego ooфós (cfr. Ep. 95, 7). O mundo antigo, em geral, e no movimento estóico, em particular, o sábio e o virtuoso são termos inter-cambiáveis, já que toda virtude se funda na verdade. Desta concepção deriva um ideal aristocrático da amizade, visto que a amizade depende de um conhecimento, que está ao alcance, somente, de uma elite intelectual (cfr. L. Pizzolato. L'idea di amicizia nel mondo antico clasico e cristiano (Turín, Einaudi, 1993), p. 7; y A. Banateanu. La théorie stoïcienne de l'amitié. Essai de reconstruction (Friburgo-París, Éditions Universitaires de Fribourg-Cerf), 2001, pp. 167-169; especialmente, sobre sophos y spoudaios en el estoicismo, véase D. Tsekourakis. Studies in the Terminology of Early Stoic Ethics (Wiesbaden, Hermes Heft 32, 1974), pp. 126-129).
} 


\section{Journal of Ancient Philosophy Vol. II 2008 Issue 1}

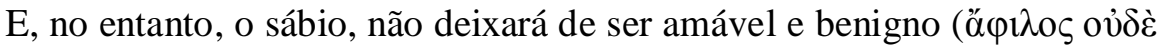

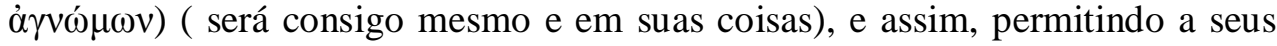
amigos quanto se permita a si mesmo, será, ao mesmo tempo inteligente, o

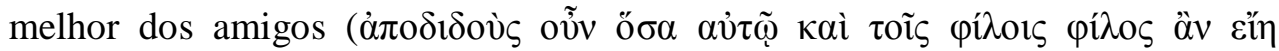

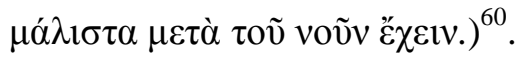

O homem "sábio e feliz" atua guiado pela inteligência, o que lhe permite apontar o outro como parte de si mesmo, seguindo os princípios de seu nível superior intelectivo. Se seguimos lendo, Plotino observa que não é necessário atribuir ao

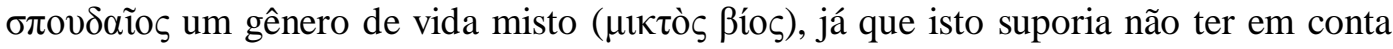
que o mesmo vive a vida da inteligência ${ }^{61}$. Este homem de bem corresponde ao "melhor dos amigos", porque define tanto aos outros como a si mesmo, a capacidade de viver a verdadeira vida, a vida segundo a inteligência. Portanto, sua amizade consiste em valorar no outro a parte superior do homem.

A amizade do sábio, do melhor dos amigos, é a do homem inteligente, ou seja, do "homem interior" que possui inteligência. Precisamente Plotino emprega a expressão "homem interior", extraída da República de Platão ${ }^{62}$, para referir-se ao "homem verdadeiro", em contraste com o composto animal ${ }^{63}$, que corresponde ao nível superior da alma (intelectivo-racional) ${ }^{64}$. Enquanto a amizade dos homens ordinários se dirige ao nível inferior da alma (sensitivo-vegetativo), a do sábio alcança o nível superior. Esta amizade intelectiva é independente dos vícios, as invejas, os ciúmes e as compaixões ${ }^{65}$. O "homem interior" não experimenta compaixão nem, por isso, pode ser amigo por piedade, já que estes sentimentos pertencem aos movimentos passionais do "homem ordinário", e são estados alheios ao homem verdadeiro.

\footnotetext{
${ }^{60}$ En. I, 4 [46] 15, 21-25. Sobre esta passagem, ver: A. Schniewind. L'éthique du sage chez Plotin. Le paradigma du spoudaios (París, Vrin, 2003), pp. 154-156.

${ }^{61}$ Cfr. En. I, 4 [46] 16, 1-13.

${ }^{62}$ Cfr. Platão, Respublica, 589a7-b1.

${ }^{63}$ Cfr. En. I, 1 [53] 10, 14-15: “- E as amizades, de quem são? - Uma do composto e outras do

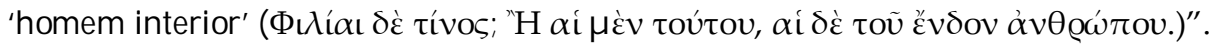

${ }^{64}$ Cfr. En. V, 1 [10] 10, 10.

${ }^{65}$ Cfr. En. I, 1 [53] 19, 12-14.
} 
Podemos observar que o sábio plotiniano se sente tocado pelo estado dos outros homens. Não permanece isolado, fechado em uma acrópolis de marfim, sem levar em consideração as preocupações éticas que envolvem os demais homens. $\mathrm{O} \sigma \pi \mathrm{ov \delta \alpha}$ ĩo se converte no melhor dos amigos porque transmite a seus amigos o que cabe a si mesmo. Enquanto "homem interior" e "inteligente" lembra ao outro que lhe convém colocar-se no caminho de regresso ao inteligível, mediante o exercício da virtude.

O homem sábio trata o outro como a si mesmo. Diferentemente do homem

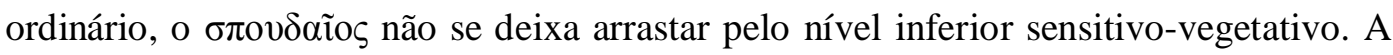
debilidade da alma leva o homem ordinário a afogar-se no sofrimento, ao tal ponto que não pode realmente permitir a seus amigos o que se permite a si mesmo, já que isto pode ameaçar sua própria tranqüilidade. Por sua parte, o homem sábio não se vê limitado por esta preocupação. Como conseguiu expulsar de sua alma os temores irracionais, pode aproximar-se do outro em grau de máxima liberdade. Deste modo, o não ver-se afetado pelos padecimentos físicos ou psíquicos facilita sua relação de alteridade, já que não tem necessidade de proteger sua própria tranqüilidade. Não é indiferente ou insensível aos outros, mas ao contrário, mantém uma grande estima e consideração pelo o outro. Considera o outro como si mesmo, ou seja, é capaz de atuar a partir do nível superior da alma. Neste sentido, é o melhor amigo do outro.

Na sua relação com o outro, o sábio o considera como sendo duplo: constituído de um nível inferior (sensitivo-vegetativo) e outro nível superior (intelectivo-racional), pelo que esta relação, com o homem ordinário, se encaixa dentro de um marco

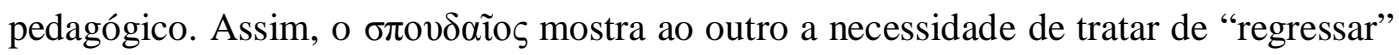
ao mundo inteligível, para viver a verdadeira vida, e de que modo, pelo exercício da virtude, pode-se empreender o caminho em direção ao Bem. Este contexto educativo, como transfundo da relação da amizade, reflete a relação que se instaura no interior de todo homem entre os dois níveis da alma. Tanto o homem ordinário como o homem sábio têm uma alma que compreende dois níveis. Mas, o ordinário "esqueceu” a existência do nível intelectivo-racional de sua alma. A relação de amizade entre o sábio

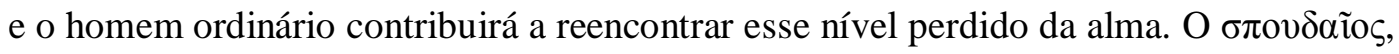
exercendo uma atividade semelhante a da alma superior sobre a inferior, tratará de guiar o homem ordinário mostrando-lhe o caminho que leva ao Bem.

\section{A amizade pura do mundo inteligível}




\section{Journal of Ancient Philosophy Vol. II 2008 Issue 1}

O sábio não viverá em solidão, já que é sociável e ativo por natureza.

Ali a divisão não é de partes confusas ainda que misturadas, mas que a 'Amizade' que se diz que reina no universo é esta, não a que se dá no universo daqui. A de aqui é uma cópia, pois é amistosa a partir de uma dissociação, enquanto que a verdadeira Amizade consiste em que todas as coisas sejam uma só e não se dissociem jamais. Porque se dissocia - diz [Empédocles] - o que está neste céu sensível ${ }^{66}$.

A Inteligência se divide em uma unimultiplicidade de formas inteligíveis; por sua vez, estas formas inteligíveis são diferentes entre elas, diferentes da Inteligência, no entanto, são a Inteligência mesma, precisamente porque é a totalidade e multiplicidade. Nesta unidade múltipla, a Inteligência é "amiga dela", como figura no livro primeiro do tratado Sobre a providência III, 2 [47]: "toda a vida daquele [Ser] é ao mesmo tempo toda Inteligência, pois é uma vida que vive na unidade e intelige juntamente; e, assim, faz que a parte seja um todo e que toda parte seja amiga dela, não que uma se separe da outra nem que uma fique isolada e desterrada das outras"67. Para expressar a relação das formas inteligíveis entre se Plotino recorre a duas fórmulas, extraídas de Anaxágoras, mas transladadas ao mundo inteligível: "todas as coisas juntas" (ó $\mu$ oṽ $\pi \alpha ́ v \tau \alpha)$ ) , e a

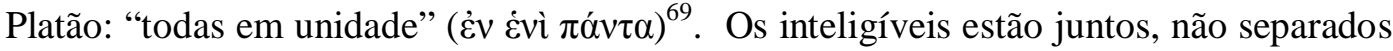

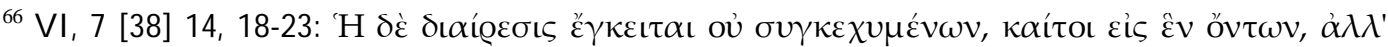

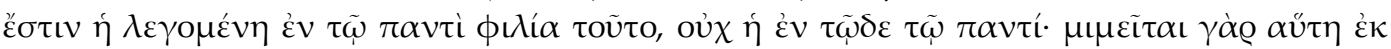

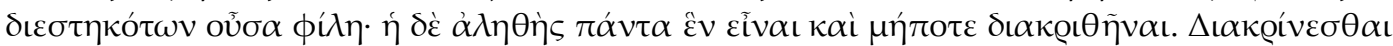

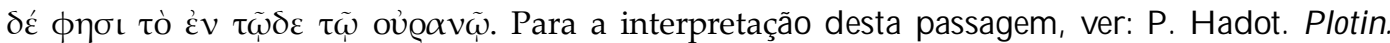
Traité 38, VI, 7, introducion, traduction et notes par P. H. (París, Cerf, 1998), pp. 254-255; y F. Fronterotta. "Traité 38 (VI, 7). Comment la multiplicié des idées s'est établie et sur le Bien", présentation, traduction et notes par F. F., en R. Dufour, F. Fronterotta, L. Lavaud \& P.-M. Morel (trad.), Plotin. Traités 38-41 (París, Flammarion, 2007), pp. 65-66, y notas. 116 y 117 (p. 137).

${ }^{67}$ En. III, 2 [47] 1, 30-32.

${ }^{68}$ Anaxágoras, fr. 1.

${ }^{69}$ Platão, Timaeus, 37 d. Cfr. En. V, 3 [49] 15, 21; V, 8 [31] 9, 1-3; VI, 5 [23] 5, 4; V, 9 [5] 9, 15; VI, 2 [43] 21, 55; VI, 5 [23] 6, 2-3; VI, 6 [34] 7, 4.
} 
nem local ${ }^{70}$ nem temporalmente ${ }^{71}$, como os corpos do mundo sensível, mas coexistem simultânea e eternamente.

Plotino contrapõe a amizade pura do mundo inteligível à amizade misturada com o ódio que reina no mundo sensível ${ }^{72}$. Para explicar esta contraposição recorre a Empédocles $^{73}$, citando-o no final da passagem. A amizade reina no Todo da Inteligência, enquanto que a amizade do universo sensível é tão somente uma imagem daquela, já que, por efeito do Ódio, a amizade dos seres sensíveis só se ajusta entre realidades completamente distintas. Por isso, a separação começa com o céu sensível por influência da força do Ódio; no entanto, a verdadeira Amizade faz que tudo seja uno e inseparável no mundo inteligível. Deste modo, ainda que encontre distinção e alteridade no mundo inteligível que torne possível a Amizade, a distinção e a alteridade se dão na unidade e sem separação. Plotino leva a cabo una exegese neoplatônica de Empédocles: quando $\Phi$ ıía triunfa, assistimos à realização de $\Sigma \varphi \alpha i ̃ \rho o \varsigma^{74}$, ou seja, do mundo inteligível, no qual não há separação, mas unidade na multiplicidade. No

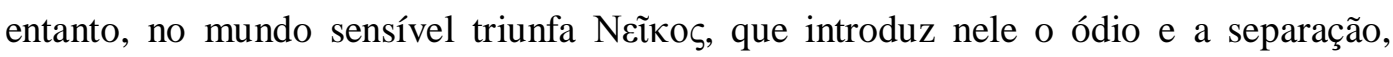
entranhando o predomínio da multiplicidade ${ }^{75}$.

Como na Inteligência as partes estão juntas, mas discriminadas, isto é, juntas mas não confusas: cada uma é tudo, mas cada uma é o que e é ${ }^{76}$. A Amizade junta todas as partes na Inteligência, precisamente porque as partes da Inteligência, os inteligíveis, ainda que estejam todos unidos na unidade, não estão confundidos totalmente uns com os outros ${ }^{77}$. As partes interiores da Inteligência estão juntas como estão juntas as partes do organismo na razão seminal como em um só centro ${ }^{78}$, mas são diferentes pela

\footnotetext{
${ }^{70}$ Cfr. En. V, 9 [5] 9, 14-16; V, 8 [31] 9, 19-23; VI, 6 [34] 7, 1-7.

${ }^{71}$ Cfr. En. V, 9 [5] 10, 9-11; V , 1 [10] 4, 21-25.

${ }^{72}$ Cfr. En. III, 2 [47] 2, 4-5.

${ }^{73}$ Empédocles, B 17, 7 y 26, 5.

${ }^{74}$ Cfr. Empédocles, B 27.

${ }^{75}$ Cfr. Simplicio, In Aristotelis de Caelo commentaria, 293, 22-23. A separação e a distinção produzem o mundo sensível.

${ }^{76}$ Cfr. En. V, 8 [31] 9, 1-2.

${ }^{77}$ Cfr. En. VI, 7 [38] 14, 18-19.

${ }^{78}$ Cfr. En. V, 9 [5] 6, 12-15.
} 
alteridade $^{79}$. Na realidade "orgânica" da Inteligência a relação da parte com o todo, o mesmo que a do mesmo com o outro, permite uma relação consigo mesmo, uma amizade consigo mesmo, demonstração de uma vida fácil, cheia de luz e esplendor, na qual tudo é transparente em tudo ${ }^{80}$.

Podemos pôr em conexão a relação consigo mesmo, da parte com o todo, com a providência. O tema da providência ( $\pi \rho$ óvota) havia sido tratado pela maior parte dos filósofos gregos desde as Leis de Platão ${ }^{81}$, com exceção de Aristóteles, ou bem para negá-la ou bem para demonstrá-la. Plotino a dedica um extenso tratado, dividido em dois livros na edição porfiriana ${ }^{82}$. A providência consiste na conformidade do mundo com a Inteligência, para o qual é preciso, primeiro, que todas e cada uma das coisas do mundo estejam bem dispostas e, segundo, que o conjunto de todas elas esteja perfeitamente coordenado. Plotino se inspira, sobre tudo, no Timeo e nas Leis de Platão e, também, nos estóicos. Os adversários que ele tem presentes são os epicúreos e os gnósticos, mas critica os estóicos, porque identificavam a providência com a fatalidade.

Nas Enéadas Plotino tenta conciliar a providência com a transcendência. Para Epicuro a felicidade dos deuses - que vivem despreocupados nos "entremundos"- é incompatível com o cuidado do governo do mundo e dos assuntos humanos. Ao contrário, Plotino defende a espontaneidade operativa da Inteligência e da Alma sem diminuição de sua transcendência. A função cósmica da segunda hipóstase consiste em emitir eternamente, “impávida e serena”, um logos que origine o mundo ${ }^{83}$. A Alma tão pouco tem preocupações ao governar este mundo somente com sua presença, sem inclinar-se nem sequer em seu nível inferior, não passa apuros, porque não tem que deliberar nem calcular para produzi-lo ${ }^{84}$.

Frente aos estóicos antigos que identificavam Deus, Inteligência, Logos, Natureza, Providência e Destino, Plotino se esforça para estabelecer uma hierarquia. O

\footnotetext{
${ }^{79}$ Cfr. En. IV, 3 [27] 5, 7-8; V, 1 [10] 4, 39-40.

${ }^{80}$ Cfr. En. V, 8 [31] 4, 1-8. Plotino faz eco a um verso da Ilíada, VI, 138.

${ }^{81}$ Cfr. Platão, Leis, 900c7 ss.

${ }^{82}$ Sobre la providencia, libros I-II (En. III, 2-3 [47-48]).

${ }^{83}$ Cfr. En. III, 2 [47] 2, 15- 24. Sobre el tema de la providencia puede verse, Jesús Igal (trad.), 1982-1998, vol. 1, 78-81.

${ }^{84}$ Cfr. En. III, 4 [15] 4, 4-6 y En. IV , 4 [28] 10, 6-10.
} 
Uno-Bem é o responsável último da providência, que a garante com sua presença ${ }^{85}$. Mas, em sentido estrito, a providência é tarefa da Alma, entendida como logos da Inteligência. Neste sentido, visto que há dois níveis de Alma, há também dois níveis de providência: uno superior, que é um logos que conecta o mundo inteligível com o sensível, e outro inferior, conectado com o anterior e autor da ordem cósmica ${ }^{86}$. O "logos do universo", que é o logos da Alma inferior, emana da Inteligência, com o concurso da Alma superior ${ }^{87}$.

De uma Inteligência una e do logos emanado dela surgiu este universo e se expandiu com o que, forçosamente, unas partes se fizeram amigas e benévolas; outras, inimigas e hostis, e se danificaram umas as outras, umas voluntária e outras involuntariamente, e umas, ao serem destruídas, produziram a gênese de outras ${ }^{88}$.

Por cima dos efeitos que as partes causam e padecem se encontra a "harmonia" do universo, produzida pelo logos que coordena o conjunto ${ }^{89}$. Ainda que a providência não seja responsável por tudo quanto sucede no mundo, ela é sim a coordenadora de tudo, desde o primeiro momento. Plotino compara a providência com um dramaturgo que, conhecendo previamente a trama de uma obra, distribui os papéis entre os atores de acordo com os méritos de cada um:

Nos dramas humanos, as palavras são distribuídas pelo autor, mas os atores põem cada um de sua parte e retiram de si mesmos a bom ou a má

\footnotetext{
${ }^{85}$ Cfr. En. VI, 7 [38] 39, 26-27.

${ }^{86}$ Cfr. En. III, 3 [48] 4, 8-13.

${ }^{87}$ Cfr. En. III, 2 [47] 16, 11-14.

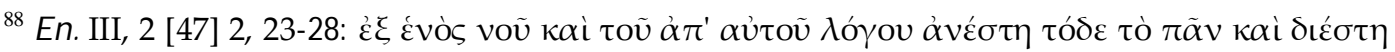

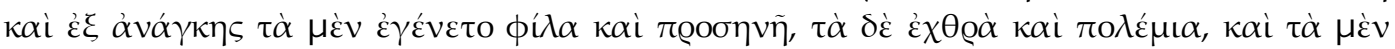

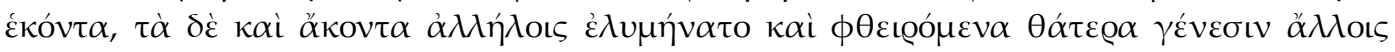

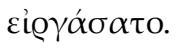

${ }^{89}$ Cfr. En. III, 2 [47] 2, 28-32.
} 


\section{Journal of Ancient Philosophy Vol. II 2008 Issue 1}

atuação, já que, depois da composição dos diálogos pelo autor, ainda há algo que lhes incumbe $e^{90}$.

Para Plotino o mundo sensível é uma imagem perfeita do mundo inteligível. Neste ponto interpreta de novo o Timeu platônico: o bom demiurgo quis fazer este mundo o mais semelhante a si mesmo e o mais semelhante a seu modelo ${ }^{91}$. A melhor das obras é o produto do melhor dos artesãos ${ }^{92}$.

Mas o modo como se originam e como estão todas e cada um das coisas deste mundo - algumas das quais dão pé, pela crença de que não se originam acertadamente, para que sobrevenham dúvidas acerca da providência sobre o mundo e para que a alguns [os epicureus] lhes sobrevenha a idéia de negar inclusive sua existência e a outros [os gnósticos] a de afirmar que o mundo é obra de um demiurgo mau-, é um tema que convém examinar tomando a discussão desde cima e desde o princípio ${ }^{93}$.

O mundo sensível, diz Plotino, é belo e "o melhor dos seres compostos de corpo"94. Porque, em primeiro lugar, este mundo existe por necessidade e surgiu não como resultado de um cálculo, mas porque existe uma natureza superior que engendra por natureza algo semelhante a si mesma. Em segundo lugar, o mundo sensível, ainda que houvesse sido o resultado de um cálculo, "é um todo sumamente belo, autosuficiente e amigo de si mesmo e de suas próprias partes, tanto das principais como das

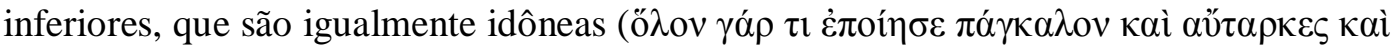

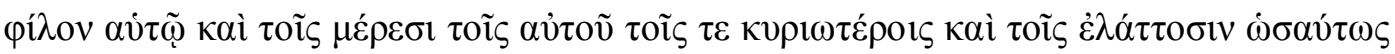

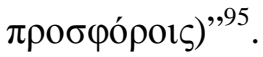

\footnotetext{
${ }^{90}$ En. III, 2 [47] 17, 29-32.

${ }^{91}$ Cfr. Platão, Timaeus, 30d.

92 Cfr. Platão, Timaeus, 30a.

93 En. III, 2 [47] 1, 5-10.

94 En. III, 2 [47] 3, 2.

95 En. III, 2 [47] 3, 6-9.
} 
Não se deve tomar como mal que os maus colham mais abundantemente o que plantam sobre a terra.

- E o que dizer da recordação dos amigos, dos filhos e da esposa? O que da pátria e das coisas é normal que recorde um homem delicado?

-Pois a parte inferior da alma recordará cada coisa com emoção, mas o homem delicado recordará essas coisas desapaixonadamente ${ }^{96}$.

A emoção $(\pi \alpha ́ \theta 0 \varsigma)$ reside inicialmente na alma inferior, e as emoções delicadas

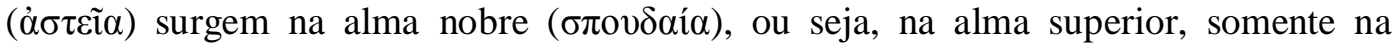
medida em que manteve certo consórcio com a alma inferior ${ }^{97}$.

A alma inferior deve aspirar ao recordo dos atos procedentes da superior, especialmente quando é delicada desde o princípio ou pela educação que recebe da superior. Em troca, esta deve aspirar a esquecer-se dos atos procedentes da inferior. No mundo sensível "manter-se a margem dos desejos humano"98, observa Plotino citando o Fedro de Platão, constitui uma atitude excelente. Deste modo, a "alma boa e esquecidiça", já que se distancia da multiplicidade e reúne a multiplicidade na unidade, vivendo assim, sem estar sobrecarregada de coisas, mas ligeira e autônoma, desprendendo-se de tudo o que lhe é alheio.

O filósofo está disposto, por natureza, a elevar-se ${ }^{99}$. No tratado Sobre a dialética I 3 [20] ${ }^{100}$ Plotino mostra que o músico e o amante, antecessores do filósofo, poderiam superar o nível ao qual estavam encaixados, o que o leva a mostrar a separação que levam a cabo do mundo sensível: o músico e o amante necessitam separar-se do mundo sensível, enquanto o filósofo não necessita fazê-lo, o que pressupõe outras capacidades primeiras inteligíveis que não abandona nunca.

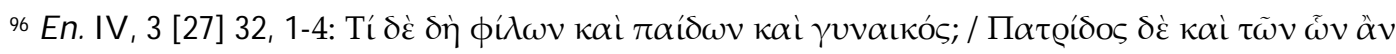

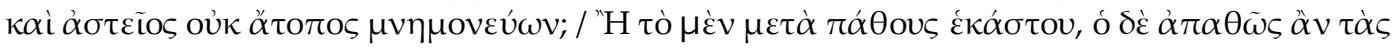

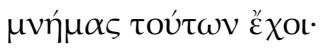

97 Cfr. En. IV, 3 [27] 32, 4-6.

98 Cfr. Platão, Phaedrus, 249c8-d1.

${ }_{99}$ Cfr. En. I, 3 [20] 3, 1.

100 Cfr. En. I, 3 [20] 2.
} 
Assim, pois, o filósofo encarna este tipo geral e, ao mesmo tempo, modelar, tanto em seus comportamentos como em suas práticas. A disposição natural para elevar-

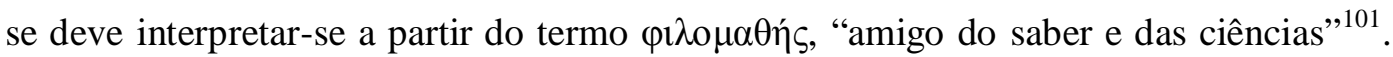
Como o amante está dominado por seu desejo, produto de uma busca insatisfeita derivada da falta e da necessidade de dirigir-se às belezas sensíveis, é preciso "acostumar-se"102, fazê-lo pensar, sem que possa ser autônomo. Deste modo, na relação amorosa descobriria ao outro, mas à custa de ceder uma cota de sua liberdade, prisioneira do desejo, submetida aos azares do amor. Por sua parte, o filósofo é mais livre, despreendido da influência excessiva do corpo. Não que ele esteja menos enamorado, mas enamorado do saber, pelo que não está separado de todo do eros

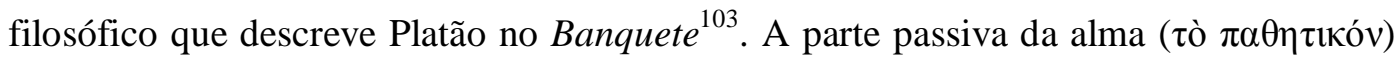
se opõe à parte racional ( homem, ambas fiquem completamente desassociadas ${ }^{104}$.

Referências Bibliográficas

Atkinson, M. J. Plotinus: Ennead V, 1. On the three principal hypostases. A commentary with translation (Oxford University Press, 1983).

Baeumker, C. Das Problem der Materie in der griechischen Philosophie. Eine historisch-kritische Untersuchung (Münster, 1890).

Banateanu, A. La théorie stö̈cienne de l'amitié. Essai de reconstruction (Éditions Universitaires de Fribourg-Cerf, 2001).

Blumenthal, H.-J. "Soul, World-Soul and Individual Soul in Plotinus", Le Néoplatonisme (C.N.R.S., 1971), pp. 55-63.

Charrue, J.-M. Illusion de la dialectique et dialectique de la l'illusion. Platon et Plotin (Les Belles Lettres, 2003).

\footnotetext{
${ }^{101}$ Cfr. En. I, 3 [20] 3, 7.

102 Cfr. En. I, 3 [20] 2, 5-6. Véase J.-M. Charrue. Illusion de la dialectique et dialectique de la l'illusion. Platon et Plotin (París, Les Belles Lettres, 2003), pp. 330-340.

103 Cfr. Platão, Symposium, 203d7-8.

${ }^{104}$ Cfr. M. Dixsaut. Le natural philosophe. Essai sur les Dialogues de Platon (París, Les Belles Lettres, 1985), p. 155.
} 
Dillon, J. "Plotino y su tratado, Sobre si los astros influyen [Enn. II 3]", MHNH. Revista Internacional de Investigación sobre Magia y Astrología Antiguas, 3, 2003, pp. 149158.

Dixsaut, M. Le natural philosophe. Essai sur les Dialogues de Platon (Les Belles Lettres, 1985).

Fronterotta, F. “Traité 38 (VI, 7). Comment la multiplicié des idées s'est établie et sur le Bien", présentation, traduction et notes par F. F., en R. Dufour, F. Fronterotta, L. Lavaud \& P.-M. Morel (trad.), Plotin. Traités 38-41 (GF Flammarion, 2007).

Graeser, A. Plotinus and the Stoics (Brill, 1972).

Hadot, P. Traité 9, VI, 9, introduction, traduction et notes par P. H. (Cerf, 1994).

Hadot, P. Plotin. Traité 38, VI, 7, introducion, traduction et notes par P. H. (Cerf, 1998).

Laurent, J. (ed.) Les dieux de Platon (Presses Universitaires de Caen, 2003).

Laurent, J. “L'autarchie du sage selon Plotin”, Études platoniciennes, III, 2006, pp. 131139.

Meijer, P. A. Plotinus on the Good or the One (Enneads VI 9). An analytical commentary (J. C. Gieben, 1992).

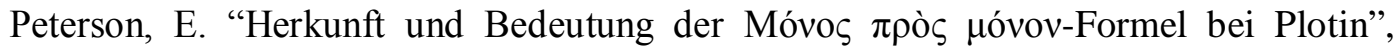
Philologus, 88, 1933, pp. 30-41

Pizzolato, L. L'idea di amicizia nel mondo antico clasico e cristiano (Einaudi, 1993).

Pradeau, J.-F. "L'assimilation à dieu”, in J. Laurent (ed.) Les dieux de Platon (Presses Universitaires de Caen, 2003), pp. 41-52.

Rivaud, A. Le problème du devenir et la notion de la matière dans la philosophie grecque depuis les origines jusqu'à Théophraste (Félix Alcan, 1905).

Rutten, Ch. "La doctrine des deux actes dans la philosophie de Plotin", Revue philosophique de la France et de léétranger, 81, 1956, pp. 100-106.

Schniewind, A. L'éthique du sage chez Plotin. Le paradigma du spoudaios (Vrin, 2003).

Sinnige, Th. G. Matter and infinity in the Presocratic Schools and Plato (Van Gorcum, 19712).

Tsekourakis, D. Studies in the Terminology of Early Stoic Ethics (Hermes Heft, 1974).

Vidart, Th. “'Il faut s'enfuir d'ici': la relation de l'homme au monde”, Études platoniciennes, III, 2006, pp. 141-152.

Zamora, J. Ma . "Entre la Academia y el Pórtico. La sympátheia en Plotino", Revista Latinoamericana de Filosofía, 29, 2003, pp. 97-122.

[Traduzido por Cícero Bezerra e revisto por Marco Zingano] 